\title{
Oncology
}

Barrington J.A. Furr (Ed.)

\section{Aromatase Inhibitors}

Series: Milestones in Drug Therapy

192 p., CHF 208.-/EUR 128.-, Birkhäuser, 2006

ISBN 3-7643-7199-4

Tamoxifen, the veteran antiestrogen, continues to be used worldwide for the treatment of all stages of breast cancer. The medicine is recognized to have changed our ability to target drugs to treat cancer with minimal side effects. However, tamoxifen is not a pure or complete antiestrogen but a selective estrogen receptor modulator (SERM). Despite the fact that tamoxifen is an antiestrogen in breast tumors, the drug has estrogen-like actions in uterine tissue. This SERM action is expressed as an increase in the incidence of endometrial cancer in postmenopausal women. Another small but significant problem is an increase in the incidence of blood clots - again an estrogen-like action. Finally, tamoxifen's estrogen-like pharmacology results in a unique forum of drug resistance/tamoxifen-stimulated tumor growth. However, problems create solutions. The current solution for the treatment of estrogen-stimulated tumor growth is not to treat it with an SERM but to have no estrogen at all, starving the tumor of the fuel needed to maintain the engine of survival. Enter the aromatase inhibitors that block estrogen synthesis in postmenopausal women.

Dr. Barrington Furr, the editor of and contributor to this valuable summary of aromatase inhibitors, has drawn upon his professional status and skills as an endocrinologist to assemble an outstanding group of investigators to contribute to this volume in the series Milestones in Drug Therapy.
Each of the authors has played and continues to play an important role in the evolution of aromatase inhibitors as therapeutic agents. This is what makes this book so valuable.

Dr. William Miller and Dr. Angela Brodie must be credited as pioneers in the development of aromatase inhibitors as useful therapeutic agents long before the modern era of targeted drug therapy. The chapters by Miller and Brodie reflect their nearly $40-$ year commitment to the target (in and around the tumor), the aromatase enzyme, and the solution, the development of the first truly targeted aromatase inhibitor, 4-hydroxyandrostenedione or formestane.

What is particularly good about the book is the synthesis of basic research with clinical advances. The volume has a wide appeal. Also, the work is a testimony to the clinical investigators who have systematically built upon and around the success of tamoxifen to refine the treatment of breast cancer. Study designs comparing aromatase inhibitors against adjuvant tamoxifen, after a full 5 years of adjuvant tamoxifen or after a few years of tamoxifen, have uniformly demonstrated fewer side effects (e.g. lower incidence of endometrial cancers and blood clots) and better efficacy (e.g. increases in disease-free survival and further decreases in contralateral breast cancers). Most importantly, the overview analysis of the combined randomized trials shows an overall survival advantage. The aromatase inhibitors are undoubtedly a valuable asset for health care systems overall. The only global issue is cost but this will be resolved in a decade when patents have expired.

I enjoyed this book and the outstanding list of accomplished authors make it essential reading for a wide range of medical oncologists, surgeons and especially fellows in training.

V. Craig Jordan, Philadelphia, Pa.

\section{KARGER}

(c) 2006 S. Karger AG, Basel

Fax +41613061234 E-Mail karger@karger.ch www.karger.com 